\title{
Improvement of Mango Tree Architecture
}

\author{
I.S.E. Bally and P.T. Ibell \\ Horticulture and Forestry Science \\ Department of Agriculture Fisheries and Forestry \\ Queensland \\ Australia
}

Keywords: Mangifera indica, small tree, high density, pruning, training, canopy shape

\begin{abstract}
This paper discusses the role of mango canopy architecture in mango productivity and orchard management and considers potential increases on production of high density orchards through improved canopy architecture. Lower tree height, reduced vigour and smaller more open canopies are recognised as important aspects of high density orchards. However, vigour management, light relations, flowering and crop load of high density orchards needs to be better understood if we are to developed sustainable highly productive canopy training and pruning systems that are easy to maintain at high planting densities.
\end{abstract}

\section{TREE CANOPY ARCHITECTURE}

Tree canopy architecture is the arrangement of the structural components of a canopy and can be described by the shape, size, and spatial arrangement of branches, twigs, leaves, flowers and fruit. Tree canopy architecture can also be described by its response to environmental constraints, phenological processes and adjacency (topology). The architectural form (phenotype) of a canopy results from the interaction of genetic, environmental and management influences. Aspects of canopy architecture such as tree vigour, branch angle, canopy spread, foliage density and the average number of fruit retained per terminal are heavily influenced by tree genetics, however these can be altered to a greater or lesser extent by the environment and management practices such as planting density, pruning, branch training, rootstock, flowering and crop load thinning. Thus, to develop highly productive tree canopies, branch training and management practices have to be matched with the cultivar. Not all cultivars will be suited to intense management.

The common mango (Mangifera indica L.) is a large evergreen tree that bears flower panicles and fruit on branch terminals with a typically irregular, biennial bearing habit. Mango canopy architecture was described by Halle et al. (1978) as poly-axial with a two-phase asynchronous growth habit. The first phase has upright apical growth that occurs during seedling development. The second phase has a series of herbaceous reiterations (branches) of the active meristems of terminals or axes. Asymmetric growth of the reiterated branch complexes widens the canopy to take maximum advantage of the available light resources. This description is generalised and does not address the specific aspects of tree architecture that influence flowering, productivity, fruit quality and tree management.

The architectural development of mango canopies is influenced by the strength and order of phenological growth events. The general sequence of these growth events follows an annual cycle where a series of summer vegetative flushes that start after fruit harvest are followed by a dormant period during the winter dry season. The dormant period is then broken by flowering that proceeds to fruit set and fruit development. Fruit are generally harvested just before they ripen after which the vegetative flush cycle starts again. There are significant variations in this generalised phenology model between individual trees, cultivars, seasons and tropical and subtropical environments. For example, the number and timing of vegetative flushes will influence tree vigour and subsequent flowering and cropping. The percentage of terminals that flower and the number of fruit retained to full maturity influence subsequent flushing and vigour, canopy 
openness and shape.

When left to grow to their natural full size, many mango cultivars develop in to tall trees (up to $40 \mathrm{~m}$ ) with large open spreading canopies that are difficult to manage with relatively low yields per orchard unit area. In a commercial orchard situation, well managed trees are not left to grow to full size, but pruned annually to reduce the canopy height, shape, and density to promote productivity. However, in many older traditional orchards trees are still relatively large when compared to other fruit species such as apples and stone-fruit.

\section{MANGO EVOLUTION}

Some evolutionary adaptations of the mango, such as tall tree height and high tree vigour, are thought to have arisen as a response to competition for sunlight early in the development of the species when it originated in the tropical rainforests of South and South Eastern Asia (Wolstenholme and Whiley, 1995). Other adaptations are thought to have arisen in response to the hot, dry seasonal monsoonal environment (Bompard, 2009) that is closer to mangoes preferred environment today. These include a tap root system which assists with flood tolerance, long-lived sclerophyllous leaves that facilitate resource hoarding and recycling, resin ducts that assist in turgor maintenance and irregular or mass fruiting (biennial bearing habit) to take advantage of seasonal variation (Wolstenholme and Whiley, 1995). Although mango fruiting is moderately energy and mineral efficient, many of the adaptations mentioned above require a considerable carbon investment, possibly at the expense of fruiting potential. By improving our understanding the ecophysiology, phenology and growth of mango we will be in a better position to reduce seasonal stress and counteract potential yield constraints through management and manipulation of the tree.

\section{ASPECTS OF MANGO TREE ARCHITECTURE}

There are several aspects of mango canopy architecture that influence tree productivity that can be managed through genetic selection or management interventions.

\section{Tree Height and Vigour}

Tall trees present several problems for orchardists. Tall mango trees cast long shadows on their own canopies and on adjacent rows reducing the photosynthetic active radiation resulting in lower vegetative growth, floral induction and yield (Dambreville et al., 2013; Sharma and Singh, 2006). The tops of tall trees are difficult to reach making effective spray application difficult and harvesting slow and complicated.

The major contributor to excessive tree height is high tree vigour which can be characterised by excessive long and thick vegetative flushes. In vigorous trees, excessive flushing uses stored carbohydrate reserves that are often not replenished in time to support a strong flowering. This results in lower and more irregular flowering and lower biennial yields. Shorter trees with less vigorous canopies can be grown at higher tree densities to improve productivity per orchard unit area. Shorter trees also have more accessible canopies and are easier to harvest, prune and spray, and hence require less labour inputs.

Many of the traditional mango cultivars selected before the $20^{\text {th }}$ century are large, highly vigorous, low yielding cultivars, when compared to other fruit species. These cultivars are traditionally planted at lower densities $(10 \times 12 \mathrm{~m})$ and associated with poor yields per orchard unit area (Fivas et al., 1997; Stassen et al., 2000). There are several semi-dwarf mango cultivars grown commercially that overcome some of the problems of excessive tree height and vigour such as 'Keitt', 'Calypso' and 'Brooks' which are planted at higher tree densities $(7 \times 4 \mathrm{~m})$. Semi-dwarf cultivars are generally higher yielding than larger cultivars and represent the early stages in the trend to smaller high production mango trees.

Some of the issues associated with tall trees have been partially overcome by low planting densities that increase the space between trees and rows and limiting tree height 
to ensure adequate light interception. Managing tree height and vigour is currently done by pruning and with the assistance of hormonal chemicals such as Paclobutrazol (Kulkarni, 1988; Singh and Janes, 2000; Vazquez-Valdivia et al., 2009).

In other fruit species, dwarfing rootstocks are used to manage tree vigour (Kulkarni, 1991). In mango there have been some reports of vigour controlling rootstocks (Ramos et al., 2004; Reddy et al., 2003; Vazquez-Valdivia et al., 2000) but very few commercial plantations rely on rootstocks to manage tree vigour. Discovery of efficient vigour managing rootstocks or interstocks in mango still remains an important area of research.

\section{Canopy Density and Spread}

Dense leaf and branch growth within a mango canopy severely restricts light penetration and airflow through the canopy. In other crops such as apple it is well documented that internal tree shading can reduce yield, fruit size, colour and total soluble solids (TSS) (Doud, 1980; Warrington et al., 1996). Shading within the canopy reduces photo-saturation of leaves and reduces the conversion of light energy to carbohydrates for growth and cropping. In dense mango canopies many leaves are in total shade and heavy shading eventually results in poor canopy regeneration, lower floral initiation (Dambreville et al., 2013), fruit set and yield (Sharma et al., 2006). Dense canopies also provide moist environments inductive to pests and diseases such as fruit spotting bugs (Amblypelta sp.) and make spray penetration more difficult.

Canopy surface area to volume ratio is lower in wider spreading canopies than in narrower compact canopies, and because mango is predominantly a terminal bearer the potential cropping points are also lower in wider spreading canopies. As such wider spreading canopies are theoretically less productive than compact canopies on a per orchard unit area basis. While more canopy over the ground provides greater light interception efficiency, it is the light distribution within the canopy that reduces the negative effects of shading. Conversely, open canopies encourage better fruit quality by allowing greater light, airflow and blush development on fruit.

Canopy spread is currently managed through annual pruning but effective opening-up of dense canopies requires biannual pruning which, if not carried out at the correct time can reduce subsequent flowering. Alternative canopy training systems and improved vigour control may offer alternate ways of managing canopy density and spread to better suit high density orchards. Canopy density and spread are traits that are under strong genetic influence and as such cultivar selections may be as important as training and management.

\section{Fruit Bearing}

The average number of fruit on a terminal at harvest varies greatly between varieties. In 'Kensington Pride' and 'R2E2', fruit retention it is often as low as 0.1 and 0.4 fruit per terminal, respectively, with most panicles retaining a single mature fruit at harvest. Other cultivars hold multiple fruit per terminal at harvest such as Palmer (2-6 fruit) and 'Keitt' (1-4 fruit). Some non-commercial varieties such as Creeper can hold more that 20 fruit per terminal.

Breeding and selection for genotypes that bear multiple fruit per terminals has great potential to increase tree yields. However, fruit from multiple fruiting terminals (510 per panicle) often have reduced fruit quality due to rub blemishes or insect infestation. Ideally two to three well spaced fruit on a panicle avoids blemishes and increases tree yield. Although the number of fruit retained to maturity on a panicle is primarily a genetic trait it can be influenced by management and environmental conditions such as pruning (Oosthuyse and Jacobs, 1997; Yeshitela et al., 2005), the application of polyamines or hormones (Ahmed et al., 2012); (Malik and Singh, 2006; Notodimedjo, 2000) nutrition (Gupta and Brahmachari, 2004) or temperature (Dag et al., 2000; Sukhvibul et al., 2000, 2005). 


\section{POTENTIAL FOR IMPROVEMENT IN MANGO TREE ARCHITECTURE}

Average international mango yields were reported by Wolstenholme and Whiley (1995) for the late 1990's as ranging from 2-12 t ha ${ }^{-1}$ for India, Philippines (Verheij, 1991), Malaysia, South Africa (Chadha and Pal, 1993), Indonesia and Thailand. Increased yields have been reported in Puerto Rico and Florida under 'good management' often exceeding 20-30 t ha $^{-1}$ (Oosthuyse, 1993). While mango productivity varies with cultivar, variations in yield can also be attributed to a range of physiological traits planting densities and management practices.

The relative high vigour and size of traditional mango cultivars compels low planting densities which is a main contributor to mangoes current low productivity per hectare. Inconsistency of flowering terminals, fruit set and the low numbers of fruit retained per panicle also contribute to the characteristic the low yields of mango (Reddy and Singh, 1990, 1991) particularly in the tropics (Whiley, 1993). In Australia, yields of traditional mango cultivars are relatively low with 'Kensington Pride' averaging $10 \mathrm{t}$ at 185 trees ha $^{-1}$ and 'R2E2' averaging $12.3 \mathrm{t}$ at 222 trees ha ${ }^{-1}$ compared with some of the semi-dwarf cultivars such as 'Calypso' averaging $7.5 \mathrm{t}$ at 318 trees ha $^{-1}$ at 3 years old and 'Keitt' averaging $16.4 \mathrm{t}$ at 318 trees ha $^{-1}$ (Williams and Holmes, 2006).

Increased yields in high density mango orchards is well supported in a number of cultivars such as 'Amrapali' $13.9 \mathrm{t} \mathrm{ha}^{-1}$ (Vishal et al., 2007), 'Sensation' $31.3 \mathrm{t} \mathrm{ha}^{-1}$ (Fivaz and Stassen, 1997), 'Tommy Atkins' 17.4-23.3 t ha' ${ }^{-1}$, 'Keitt' 29-35 t ha' (Oosthuyse, 2009). However, these systems require increased canopy pruning and training to maintain the increased yields. However, without increased canopy management, progressive decline in productivity is often observed as trees get older due to overcrowding and lower light penetration (Sharma and Singh, 2006). Fivaz et al. (1997) showed that by training high density mango trees (1000 trees $\mathrm{ha}^{-1}$ ) on a central leader system, high yields were easier to maintain that other training systems. Further research in to training systems for high density mango orchard could improve their regularity and sustainability.

In other species such as apple grown in Queensland, Australia, productivity has increased from between $10-15 \mathrm{t} \mathrm{ha}^{-1}$ to over $100 \mathrm{tha}^{-1}$ in the past 20 years by combining high density planting with trellising, training systems to optimise light interception and diffusions and rootstocks that reduce canopy vigour (Willkie, pers. commun.). It remains to be shown if similar increases in mango productivity are possible through high density orchard systems.

Adaption of mango to facilitate high density orchard productivity, reliability and fruit quality can be achieved through genetic modification, canopy training and pruning systems that maximise the water, nutrition and light environments for efficient growth at high density. It is likely that tree genetics will facilitate and limit the potential of training and pruning management options, making many of the current commercial cultivars unsuited to high density orchard systems.

One of the most important genetic contributions to high density orchards systems will be low vigour or dwarf cultivars with high precocity (early and regular bearing) and productivity. Without these characteristics the training and pruning of high density canopies will be labour intensive and stimulate vegetative rather than reproductive growth. Other genetic traits that have potential to contribute to productivity are multiple bearing panicles, high photosynthetic efficiency and low environmental stimuli required for floral induction.

Rootstock and interstock genetics may also play a role in reducing tree vigour, increased precocity and increasing the partitioning of assimilates to fruit production (harvest index). Rootstocks are critical components of high density systems in other species such as apple. In mango there have been some reports of vigour controlling rootstocks (Ramos et al., 2004; Reddy et al., 2003; Vazquez-Valdivia et al., 2000) but effects are often scion specific and yields are also lower. These and other vigour controlling rootstock need to be investigated over a wider range of scion cultivars and in combination with high density training systems.

Conventional tree training and pruning systems that have been developed in 
medium to high vigour cultivars and are generally not suited to high density orchards as they eventually result in competitive growth, excessive shading and poor flowering (Dambreville et al., 2013). Lower vigour cultivars are more suited to alternative canopy training systems with potential to maximise flowering terminals and optimise the light and shade.

In Queensland, Australia, a small tree high productivity initiative has begun to investigate high density and architecture training systems on mango productivity. The research will investigate vigour management systems (rootstocks and scion), tree light relations, crop load, canopy development and management. This research in combination with breeding new low vigour scion cultivars is expected to lead to significantly improve crop regularity and productivity on an orchard unit area basis.

\section{Literature Cited}

Ahmed, W., Tahir, F.M., Rajwana, I.A., Raza, S.A. and Asad, H.U. 2012. Comparative evaluation of plant growth regulators for preventing premature fruit drop and improving fruit quality parameters in 'Dusehri' mango. International Journal of Fruit Science 12:372-389.

Bompard, J.M. 2009. Taxonomy and systematics. p.19-41. In: R.E. Litz (ed.), The Mango, Botany, Production and Use, $2^{\text {nd }}$ Edition. CAB International, Wallingford, Oxen.

Chadha, K.L. and Pal, R.N. 1993. The current status of the mango industry in Asia. Acta. Hort. 341:42-54.

Dag, A., Eisenstein, D. and Gazit, S. 2000. Effect of temperature regime on pollen and the effective pollination of 'Kent' mango in Israel. Sc. Hort. 86:1-11.

Dambreville, A., Lauri, P.-É., Trottier, Guédon, Y. and Normand, F. 2013. Deciphering structural and temporal interplays during the srchitectural development of mango trees. Journal of Experimental Botany 64:2467-2480.

Doud, D.S. 1980. Influence of altered light levels on growth and fruiting of mature 'Delicious' apple trees. J. of Am. Soc. for Hort. 105:325-328.

Fivas, J., Stassen, P.J.C. and Grove, H.G. 1997. Pruning and training strategies for Tommy Atkins and Sensation Mango trees in higher density hegerow systems. S.A. Mango Growers' Association Yearbook 17:37-40.

Fivaz, J. and Stassen, P.J.C. 1997. The role of training systems in maintaining higher density mango orchards. Acta Hort. 455:407-412.

Gupta, R.K. and Brahmachari, V.S. 2004. Effect of foliar application of urea, potassium nitrate and NAA on fruit retention, yield and quality of mango cv. 'Bombai'. The Orissa J. of Hort. 32(2):7-9.

Halle, F., Oldeman, R.A.A. and Tomlinson, P.B. 1978. Tropical Trees and Forests: an Architectural Analysis. Springer-Verlag., Berlin.

Kulkarni, V.J. 1988. Chemical control of tree vigour and the promotion of flowering and fruiting in mango (Mangifera indica L.) using paclobutrazol. J. Hort. Sc. 63:557-566.

Kulkarni, V.J. 1991. Tree vigour control in mango. Acta Hort. 291:229-234.

Malik, A.U. and Singh, Z. 2006. Improved fruit retention, yield and fruit quality in mango with exogenous application of polyamines. Sc. Hort. 110:167-174.

Notodimedjo, S. 2000. Effect of $\mathrm{GA}_{3}$, NAA and CPPU on fruit retention, yield and quality of mango (cv. 'Arumanis') in East Java. Acta Hort. 509:587-600.

Oosthuyse, S.A. 1993. Tree spacing trends and options for yield improvement in mango. S.A. Mango Growers' Association Yearbook 13:34-39.

Oosthuyse, S.A. 2009. Management of Tommy Atkins, ultra-high density orchard and recognised benefits associated with small tree orchards. Acta Hort. 820:325-338.

Oosthuyse, S.A. and Jacobs, G. 1997. Flowering synchronization of 'Sensation' mango trees by winter pruning. Acta Hort. 455:422-430.

Ramos, V.H., Pinto, A.C.Q., Junqueira, N.T.V., Gomes, A.C., Andrade, S.M.R. and Cordeiro, M.C.R. 2004. Effect of mono and polyembryonic rootstocks on growth, yield, and fruit quality of four mango cultivars in the central reigon of Brazil. Acta 
Hort. 645:201-207.

Reddy, Y.T.N. and Singh, G. 1991. Further studies on the relationship between leaf number and area and fruit development in mango Mangifera indica L. J. Hort. Sc. 66:471-478.

Reddy, Y.T.N., Kurian, R.M., Ramachander, P.R., Singh, G. and Kohli, R.R. 2003. Longterm effects of rootstocks on growth and fruit yielding patterns of 'Alphonso' mango (Mangifera indica L.). Sc. Hort. 97:95-108.

Reddy, Y.T.N. and Singh, G. 1990. Relationship between leaf area and leaf number on fruit development in mango (Mangifera indica L.). Garten 55:138-141.

Sharma, R.R. and Singh, R. 2006. Effect of pruning intensity on light penetration and leaf physiology in Amrapali mango trees under high-density planting. Tropical Science 46:16-19.

Singh, Z. and Janes, J. 2000. Regulation of fruit set and retention in mango with exogenous application of polyamines and their biosynthesis inhibitors. Acta Hort. 509:675-680.

Sukhvibul, N., Whiley, A.W. and Smith, M.K. 2005. Effect of temperature on seed and fruit development in three mango (Mangifera indica L.) cultivars. Sc. Hort. 105:467474.

Sukhvibul, N., Whiley, A.W., Smith, M.K. and Hetherington, S.E. 2000. Susceptibility of mango (Mangifera indica L.) to cold-induced photoinhibition and recovery at different temperatures. Australian Journal of Agricultural Research 51:503-513.

Vazquez-Valdivia, V., Perez-Barraza, M.H., Osuna-Garcia, J.A. and Urias-Lopez, M.A. 2009. Integral management of Ataulfo mango orchards with high plabtation densities. Rev. Chapingo Ser. Cienc. For. Am. 15:155-160.

Vazquez-Valdivia, V., Salazar-García, S. and Peréz-Barraza, M.H. 2000. 'Esmeralda' interstocks reduce 'Ataulfo' mango tree size with no reduction in yield: results of the first five years. Acta Hort. 509:291-296.

Verheij, E.W.M. 1991. Mangifera indica L. p.203-216. In: E.W.M. Verheij and R.E. Coronel (eds.), Plant Resources of South-East Asia 2. Edible Fruits and Nuts. Pudoc.

Vishal, N.A.T., Bikash, D.A.S. and Mathura, R.A.I. 2007. Standardization of high-density planting in mango (Mangifera indica) under sub-humid alfisols of eastern India. Indian Journal of Agricultural Research 77:3-7.

Warrington, I.J., Stanley, C.J., Tustin, D.S., Hirst, P.M. and Cashmore, W.M. 1996. Light transmission, yield distribution, and fruit quality in six tree canopy forms of 'Granny Smith' apple. Journal of Tree Fruit Production 1:27-54.

Whiley, A.W. 1993. Environmental effects on phenology and physiology of mango - a review. Acta Hort. 341:168-176.

Williams, B. and Holmes, R. 2006. MG04004. Review of Mango Production Practises. Horticulture Australia, Brisbane. p.106.

Wolstenholme, B.N. and Whiley, A.W. 1995. Ecophysiology of the mango tree as a basis for pre-harvest management. S.A. Mango Growers' Association Yearbook 15:10-17.

Yeshitela, T., Robbertse, P.J. and Stassen, P.J.C. 2005. Effects of pruning on flowering, yield and fruit quality in mango (Mangifera indica). Aust. J. Exp. Agric. 45(10):13251330. 